\title{
ANÁLISE DA INFLUÊNCIA DO LOTE MÍNIMO DE COMPRAS NO CONTROLE DE ESTOQUE DE UMA EMPRESA AUTOMOBILÍSTICA
}

\author{
ANALYSIS OF THE INFLUENCE OF THE MINIMUM LOT OF PURCHASES ON THE INVENTORY \\ CONTROL OF AN AUTOMOTIVE COMPANY
}

\section{Gabriela Constantino Fenili ${ }^{1}$, Fernando de Araújo ${ }^{2 *}$, Aline Gonçalves dos Santos ${ }^{3}$, Naiara Faiad Sebba Calife ${ }^{4}, \&$ Vanessa Aparecida de Oliveira Rosa ${ }^{5}$}

1234 Faculdade de Engenharia da Universidade Federal de Catalão

5 Universidade Federal de Uberlândia

1 gabifenili8@gmail.com $2 * \underline{\text { faraujo@ufcat.edu.br }}{ }^{3} \underline{\text { aline santos@ufcat.edu.br }}{ }^{4} \underline{\text { naiaracalife@ufcat.edu.br }}$ 5 vanessaaor@ufu.br

\section{ARTIGO INFO.}

Recebido em: 21.07.2021

Aprovado em: 17.12.2021

Disponibilizado em: 20.12.2021

Palavras-chave:

Indústria automobilística; Gestão de Estoques; Lote Mínimo.

\section{KEYWORDS:}

Automotive Industry; Inventory Management; Minimum Lot.

*Autor Correspondente: Araújo, F., de.

\section{RESUMO}

O setor automobilístico tem se mostrado um potencial estratégico considerado atividade chave no processo de industrialização do Brasil (Kischner \& Viegas, 2018). Nesse sentido, como justificativa para o estudo destaca-se que o planejamento/processo de gestão de compras pode representar um ganho para a empresa, uma vez que pode minimizar prejuízos e evitar grandes volumes de capital imobilizado. Neste aspecto, este estudo tem como objetivo apresentar uma proposta de melhoria para analisar a influência da negociação de lote mínimo de itens perecíveis em uma indústria automobilística. A pesquisa foi fundamentada como quali-quantitativa, de natureza aplicada, descritiva e um estudo de caso em uma empresa automobilística, utilizando a curva ABC como planejamento estratégico através do gerenciamento de estoque. Os resultados apontaram 4 itens mais descartados no ano de 2018 após análise dos dados coletados e do tamanho dos lotes mínimos de compra de cada um. Conclui-se que o fornecedor que tinham lote mínimo elevado foram os itens mais descartados, visto que esses geram maior dificuldade na gestão de compras, a qual lida com diversas restrições diariamente. Portanto, com tantas barreiras que influenciam o processo de gestão de compras de itens perecíveis, a alteração do lote mínimo para o menor valor negociável possível, representa um ganho para a empresa, pois possibilita ao comprador da peça lidar com as mudanças e restrições da rotina empresarial com maior maleabilidade.

\begin{abstract}
The automobile sector has shown itself to be a strategic potential, considered a key activity in the industrialization process in Brazil (Kischner \& Viegas, 2018). In this sense, as a justification for the study, it is highlighted that the planning/purchasing management process can represent a gain for the company, as it can minimize losses and avoid large volumes of fixed capital. In this aspect, this study aims to present a proposal for improvement to analyze the influence of negotiating a minimum lot of perishable items in an automobile industry. The research was based as quali-quantitative, applied, descriptive and a case study in an automobile company, using the $A B C$ curve as strategic planning through inventory management. The results showed the 4 most discarded items in 2018 after analyzing the data collected and the size of the minimum purchase lots for each. It is concluded that the supplier who had a high minimum lot were the most discarded items, as these generate greater difficulty in purchasing management, which deals with several restrictions on a daily basis. Therefore, with so many barriers that influence the purchasing management process for perishable items, changing the minimum lot to the lowest negotiable value possible represents a gain for the company, as it allows the purchaser of the part to deal with routine changes and restrictions business with greater flexibility.
\end{abstract}


Citação (APA): Fenili, G. C., Araújo, F., de, Santos, A. G., dos, Calife, N. F. S., \& Rosa, V. A. de O. (2021). Análise da influência do lote mínimo de compras no controle de estoque de uma empresa automobilística. Brazilian Journal of Production Engineering, 7(5), $299-311$.

\section{INTRODUÇÃO}

O setor automobilístico tem se mostrado um potencial estratégico considerado atividade chave no processo de industrialização do Brasil que proporciona maior fluxo de investimento e desenvolvimento econômico, com impactos na balança comercial e na comunidade em forma de renda e emprego, através das inovações tecnológicas, fortalecimento da cadeia de fornecedores, expansão das exportações, qualificação de mão de obra, criação de novos postos de trabalho, aumento da qualidade e segurança dos veículos (Kischner \& Viegas, 2018; Santos, Schmidt, Adami, \& Schmidt, 2021).

No Brasil, este setor tem colaborado com novas estruturas relacionadas a manufatura enxuta, o estabelecimento de novas cadeias produtivas, alterações nos projetos dos produtos, entre outras. Adicionalmente, a indústria automobilística tem contribuído para o desenvolvimento das áreas de administração, engenharia e administração da produção (Maia \& Cerra, 2006).

Levando em conta a necessidade de gerenciamento, o setor automobilístico incorpora estratégias para atender o relacionamento entre empresas montadoras, fornecedores e clientes, por conseguinte, adotam práticas na gestão de suprimentos devido a grande quantidade de componentes de um veículo e suas particularidades (Cerra \& Maia, 2008). Vale destacar que a gestão da cadeia de suprimentos (SCM) tem ganhado destaque nos últimos anos nos círculos acadêmicos e comerciais, pois está relacionada com o processo de gerenciamento e o fluxo de produtos e materiais, pode ajudar os gestores a melhorar os processos de negócio ao projetar toda a cadeia da empresa ao longo tempo, também tem como objetivo reduzir o investimento em estoques através da amarração da área de logística com a área da produção (Junior \& Carpinetti, 2019; Sweeney, 2011).

Nesse aspecto vale destacar que os automóveis apresentam uma variedade de produtos e são responsáveis por aproximadamente metade do consumo mundial de petróleo, $50 \%$ da produção mundial de borracha, $25 \%$ do vidro e $15 \%$ do aço, uma vez que são constituídos por diversos tipos de peças provenientes de diferentes fornecedores (Dicken, 2010). Segundo Medina e Gomes (2003), um automóvel é um produto com alto nível de complexidade já que é composto em média por 20 mil produtos, autopeças e materiais.

De acordo com Ballou (2001), a compra de suprimentos, matérias primas e outros componentes, são características cruciais para uma empresa. Para Wanke (2000) devem ser observados as características do produto, o comportamento da demanda, nível de exigência do mercado, grau de flexibilidade do processo de fabricação, acesso à informação em tempo real e existência de economias de escala no transporte.

De modo complementar, a gestão de estoques contempla a busca pelo mais adequado nível de estoque para atender as demandas e objetivos. Neste aspecto, diversos métodos são empregados como just-in-time (JIT) que apresenta estratégias de fornecimento de materiais, de processos e de fabricação que são flexíveis, e que aumentam significativamente a eficiência de custos, como o Lote Econômico de Compra (LEC) que corresponde à soma dos custos de realização das encomendas e de armazenagem, obtendo-se por fim o custo mínimo total de aprovisionamento, e da curva $\mathrm{ABC}$ que auxilia na tomada de decisões que envolvem grandes volumes de dados, para definição de políticas de vendas, estabelecimento de prioridades e 
programação de produção (Gonçalves, 2013; Pozo, 2000; Santana \& Piper, 2017; Reis \& Paulino, 1994; Wood, 1992).

Por outro lado, os estoques geram custos de armazenagem, relacionados a manutenção de estoque como o giro de estoque e a falta de estoque, a ineficiência de produção, os custos com perecibilidade e obsolescência, quebra, deterioração e custo de oportunidade (Slack et al., 2009; Wanke, 2000).

Nesse aspecto, a gestão de estoques é composta por uma gama de ações que auxilia os gestores a manusear, controlar e utilizar os estoques de forma correta, além de auxiliar no lote mínimo para definir qual será o lead time do fornecedor (Godinho Filho, Hayashi, \& Rufo, 2013; Martins, 2006). Em suma, a boa gestão de estoques pode gerar vantagem competitiva no mercado (Kawase \& De Paula, 2012).

É importante destacar que no Brasil o bom gerenciamento de materiais em relação ao departamento da gestão de compras vem apresentando consideráveis mudanças, uma vez que essa área está associada aos fornecedores e juntamente com a área de qualidade, para aumentar a confiabilidade e minimizar riscos (Braga, 2006; Junior \& Carpinetti, 2019).

Diante da literatura apresentada, este estudo busca avaliar em uma empresa automobilística os itens que possuíam lote mínimo de compras alto, enquanto comparados com seu o índice de descarte. Desta forma, criou-se a seguinte pergunta de pesquisa: Qual o método mais adequado para a gestão de produtos perecíveis de modo a minimizar perdas por vencimento da data de validade?

Como objetivo este estudo busca apresentar uma proposta de melhoria para analisar a influência da negociação de lote mínimo de itens perecíveis em uma indústria automobilística. Este estudo se mostra relevante, pois contribui com a literatura e apresenta potencial prático no campo da logística, na estratégia de operação referente aos estoques, o qual se baseia em um modelo de gerenciamento através da curva $\mathrm{ABC}$, lotes de compra e estoque de segurança.

\section{REFERENCIAL TEÓRICO}

\subsection{INDÚSTRIA AUTOMOBILÍSTICA}

A indústria automobilística passou por um processo de importante transformação durante o século XX com inovações relacionadas aos princípios fordistas que envolvem a engenharia e o planejamento de produção (Wood, 1991). Essas transformações vão desde restruturação da linha de produção e desenvolvimento de produtos, com uma fase denominada de acumulação flexível representada pelo Toyotismo com base no sistema jus-in-time, sob a forma da lean production (produção enxuta), cujo objetivo principal é minimizar desperdícios e prejuízos, evitar grandes volumes de capital imobilizado, aumentar a produtividade, com propostas de reprodução e reorganização produtiva baseada em inovações tecnológicas com novos métodos de produção e de trabalho (Silva \& Martins, 2015; Wood, 1992).

O sistema Toyotismo de produção apresenta vantagens competitivas no meio industrial, como: (i) redução das perdas no processo produtivo; (ii) aumento da eficiência fabril; (iii) otimização da mão de obra, (iv) máquinas e equipamentos; e (v) aumento da qualidade dos produtos (Ghinato, 2000). Nesse aspecto, a integração com o just-in-time (JIT) está ganhando cada vez 
Citação (APA): Fenili, G. C., Araújo, F., de, Santos, A. G., dos, Calife, N. F. S., \& Rosa, V. A. de O. (2021). Análise da influência do lote mínimo de compras no controle de estoque de uma empresa automobilística. Brazilian Journal of Production Engineering, 7(5), $299-311$.

mais notoriedade, especialmente no setor automotivo como modelo de gestão produtiva, pois apresenta estratégias de fornecimento de materiais, de processos e de fabricação que são flexíveis, confiáveis e que aumentam significativamente a eficiência de custos (Wood, 1992).

No entanto, todo processo produtivo está sujeito a algum tipo de perda, Ghinato (2000), Pereira e Leite (2016), e Shingo (1996) destacaram a ocorrência de perdas no processo produtivo do sistema Toyotismo: (i) superprodução; (ii) espera; (iii) transporte; (iv) processamento; (v) estoque; (vi) movimentação; e (vii) defeitos.

E para minimizar as perdas relacionadas aos estoques e por espera, e ainda obter a redução do lead time de produção, o sistema JIT possibilita estratégias de abastecimento e fazem parte das estratégias logísticas cobrindo as quatro áreas funcionais da logística: compras, fabricação/produção, distribuição e reciclagem (Bányai \& Bányai, 2017; Ghinato, 2000).

Nesse segmento, a indústria automobilística para atender o processo de gerenciamento e o fluxo de produtos e materiais, também faz uso de práticas de relacionamento entre empresas montadoras, fornecedores e clientes, através da cadeia de suprimentos (Cerra \& Maia, 2008; Sweeney, 2011).

De acordo com Ballou (2001), a gestão de suprimentos, matéria-prima e outros componentes, caracteriza um fator crucial em uma empresa. Esses componentes envolvem diversos fatores como: a seleção de fornecedores, determinação do prazo de vendas, qualificação dos serviços, previsão de demanda, entrega no tempo certo, qualidade, quantidade, custos, serviços e preços, entre outros fatores que envolvem a estratégia de operações (Baily et al., 2000; Gaither \& Frazier, 2001).

Vale destacar que a gestão da cadeia de suprimentos (SCM) tem ganhado destaque nos últimos anos, pois está relacionada com o processo de gerenciamento e o fluxo de produtos e materiais (Sweeney, 2011). A SCM pode auxiliar os gestores na tomada de decisão e nos processos de negócio, através de técnicas de planejamento para aquisição, produção, satisfação e serviços (Junior \& Carpinetti, 2019). Para Ballou (2001), a aquisição ocupa uma posição importante nas organizações, pois as matérias-primas que compõe o produto final representam de 40 a $60 \%$ dos custos onerados, então, qualquer redução dos preços na aquisição representa um aumento significativo nos lucros.

Para Wanke (2012) a cadeia de suprimentos tem permitido às empresas operarem com níveis de estoques cada vez menores. Especificamente com relação nos níveis de estoque de segurança. $\mathrm{O}$ autor ressalta que existem quatro principais decisões para formalização de uma política de estoques na cadeia de suprimentos: (i) nível de centralização dos estoques, (ii) estratégias de postergação do ressuprimento versus cálculo do ponto de pedido, (iii) políticas para correção dos estoques de segurança em função dos custos de falta e de excesso e (iv) adoção do lote econômico de compra versus o ressuprimento just-in-time.

\subsection{GESTÃO DE MATERIAIS E ESTOQUES}

Nas organizações, o estoque é encontrado como materiais em processo, no almoxarifado, materiais no setor de produção e materiais em transporte (Ching, 2001). De acordo com Martins (2006), a gestão de estoques é composta por uma gama de ações que permitem aos gestores

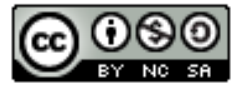


Citação (APA): Fenili, G. C., Araújo, F., de, Santos, A. G., dos, Calife, N. F. S., \& Rosa, V. A. de O. (2021). Análise da influência do lote mínimo de compras no controle de estoque de uma empresa automobilística. Brazilian Journal of Production Engineering, 7(5), $299-311$.

averiguar se os estoques estão sendo utilizados da forma correta, bem localizados, bem manuseados e bem controlados.

De acordo com Wanke (2000), uma política de estoques define: (1) quanto pedir, (2) quando pedir, (3) quanto manter em estoques de segurança, (4) onde localizar. Além disso, existem aspectos fundamentais na gestão de estoque subdivididos em três áreas: (i) a gestão de materiais; (ii) a gestão administrativa; e (iii) a gestão econômica (Braga,1996). Neste estudo vamos abordar brevemente a gestão de materiais dos estoques que compreende o modo de como é feita a armazenagem garantido a eficiência na execução e um custo mínimo.

Vale destacar que a existência de estoque na empresa gera custos de armazenagem, relacionados a manutenção de estoque como o giro e a falta de estoque, a ineficiência de produção, os custos com perecibilidade e obsolescência, quebra, deterioração e custo de oportunidade, por outro lado pode gerar valor ao produto (Slack et al., 2009; Wanke, 2000).

No caso do armazenamento dos materiais perecíveis as condições de armazenagem devem atender aos requisitos inerentes à natureza dos materiais, pois podem trazer custos para a empresa caso não tenham um processo adequado e eficaz, tornando-se um grande problema para os gestores (Bornia, 1995; Carvalho, 2010). A gestão de materiais perecíveis requer algumas exigências bem mais do que certificação de qualidade por parte dos fornecedores (Manuel, 2013).

Os Materiais perecíveis fazem parte de uma classe de itens que demanda uma gestão mais exclusiva. Os principais métodos de movimentação e controle do estoque para itens perecíveis são: FIFO (First In, First Out) é o método mais comum de movimentação, FEFO (First Exhaust, First Out) utilizado para controle de produtos conforme a sua data de validade e LIFO (Last In, First Out) utilizado nas áreas de transportes de distribuição (Paoleschi, 2014).

Outro fator importante para a gestão de estoques e para reduzir os custos inerentes ao estoque é a utilização do cálculo de lote econômico, que é definido como uma quantidade de materiais a ser adquirido pela organização no momento da compra do reabastecimento dos estoques, corresponde exatamente à soma dos custos de realização das encomendas e de armazenagem, obtendo-se por fim o custo mínimo total de aprovisionamento (Accioly et al., 2012; Gonçalves, 2013; Reis \& Paulino, 1994).

Destaca-se que a negociação do lote mínimo e múltiplo de embalagem auxilia a definir qual será o lead time do fornecedor, que será o tempo que o fornecedor demora desde a criação do pedido do cliente até que o item seja efetivamente recebido por ele para então entender qual será o ponto de ressuprimento do item (Godinho Filho, Hayashi, \& Rufo, 2013). Para Dias (2010) esses fatores constituem o tempo suficiente que levam da percepção de que o estoque necessita ser reposto até a entrada do item no estoque da empresa.

De modo complementar, destaca-se que a demanda não é totalmente estável, e para gerir este comportamento aleatório (oferta e procura), ou seja, as eventuais variações no sistema como: (i) aumento de demanda, e (ii) rejeição do lote de pedidos ou atrasos de fornecedor, tornando necessários constituir um estoque de segurança para absorver/amortecer variações superiores aos valores médios registados (Corrêa, Gianesi, \& Caon, 2001; Dias, 2010; Martins, 2006).

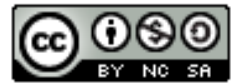


O dimensionamento do estoque de segurança vai depender do modelo de gestão de estoques implementado, como grande parte das empresas trabalham com estoque de segurança ou estoque mínimo de produtos, as entradas e saídas de estoque tornam-se fatores relevantes para a empresa, uma vez que falhas no sistema de controle desses setores podem causar falsas informações e ocasionar falhas no momento de efetuar a compra de materiais, causando alterações desnecessárias no estoque, ou seja, o sistema interpreta erroneamente a necessidade de realizar nova compra ou deixa de realizar a compra (Araújo, 2009; Moreira, 2009).

Adicionalmente, existem técnicas de gestão de estoques utilizadas para organizar os materiais como a Curva $\mathrm{ABC}$ que é muito utilizada em diversos setores para auxiliar na tomada de decisões que envolvem grandes volumes de dados, para definição de políticas de vendas, estabelecimento de prioridades, programação de produção e outros (Pozo, 2000; Santana \& Piper, 2017).

Letti e Gomes (2014) ressaltam as dificuldades de gerenciamento na gestão de estoques nas micro e pequenas empresas, uma vez que à limitação de recursos tecnológicos como sistemas de tecnologia da informação e estoques elevados podem gerar problemas de obsolescência e volume excessivo de produtos em estoque, diminuição de capital de giro, produtos com validade vencida e alto custo de estoque (Letti \& Gomes, 2014).

Embora um bom gerenciamento de estoque seja importante, a acuracidade, é um indicador de qualidade e de suma importância para manter os níveis altos de produtividade e lucratividade, definida pela fração da quantidade de itens existentes nos sistemas de controle pela relação da existência física dos itens (Sheldon, 2004). A falta de acurácia no inventário torna os estoques incertos, portanto o monitoramento dos inventários é a melhor maneira de evitar erros de contagem (Kogik, Silva, Belusso \& Werlang, 2018). Em suma, a boa gestão de estoques pode gerar vantagem competitiva no mercado (Kawase \& De Paula, 2012).

\section{Metodologia}

Quanto ao método, este estudo se trata de uma pesquisa com abordagem quali-quantitativa. Qualitativa, pois tende entender o processo através da experiência humana, e quantitativa pois tem raízes no raciocínio lógico (Polit, Becker, \& Hungler, 2004). Quanto a natureza, é uma pesquisa aplicada, que visa elaborar ideias e informações com intuito de solucionar problemas específicos (Gerhardt \& Silveira (2009). Se classifica como descritiva, pois através dos dados coletados, serão propostas hipóteses que não representam ações casuais (Aaker, Kumar, \& Day, 2004). Por fim, se classifica como estudo de caso, pois será estudado um evento moderno inserido no seu contexto diário (Yin, 2001).

O estudo foi realizado em uma empresa do setor automobilístico no sudeste goiano. Inicialmente, para a coleta de dados foram realizadas entrevistas com gestores da área em questão, visitas in loco a fim de entender o processo como um todo, além de acessos aos relatórios de indicadores referente ao ano de 2018. A pesquisa foi realizada para verificar se existe ineficiência dos itens que possuíam lote mínimo de compras alto, enquanto comparados com seu o índice de descarte. A coleta de dados e conhecimento de processos foram feitos entre agosto/2019 e novembro /2019 (Figura 1).

\section{@ $\odot \Theta \odot$}


Figura 1. Etapas de desenvolvimento do estudo.

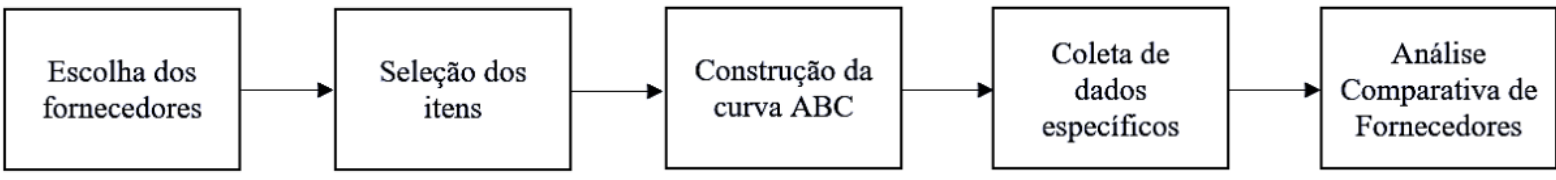

Fonte: Autores (2020)

A construção específica de cada etapa, conforme Figura 1, seguiu conforme:

- Foram escolhidos os dois fornecedores mais relevantes no fornecimento de itens perecíveis para a empresa;

- Foram selecionados todos os itens, os quais tiverem descarte por vencimento no ano de 2018, classificados como perecíveis dos fornecedores A e B;

- Foi construída uma curva ABC para os itens de cada um dos fornecedores usando como critério de seleção o valor total descartado (em reais) do item;

- A partir da classificação $\mathrm{ABC}$, foram selecionados dois itens da curva A de cada um dos fornecedores e coletados dados específicos de cada um deles, como: lote mínimo de compra, demanda média anual, quantidade de compras, quantidade de descarte (os últimos dois em unidades e valor financeiro); e

- $\quad$ Por fim, com todos os dados organizados, foram comparados os valores dos fornecedores $\mathrm{X}$ e $\mathrm{Y}$ e propostos lotes econômicos ideais de cada um dos quatro itens analisados.

\section{ANALise dos Resultados}

A partir do acesso ao arquivo de baixas de itens vencidos referente ao ano de 2018 da empresa automobilística analisada, foram filtrados apenas os itens dos fornecedores X e Y. Em seguida foram criadas duas tabelas, uma para cada fornecedor, com as informações dos itens vencidos, as quantidades e os respectivos valores totais descartados. A partir dessas duas tabelas, foi feita a curva $\mathrm{ABC}$ de cada um dos fornecedores usando como critério de seleção o valor total descartado (em reais), a fim de encontrar os dois itens mais relevantes (Figura 2).

Figura 2. Curva ABC do fornecedor $X$.

\section{FORNECEDOR X}

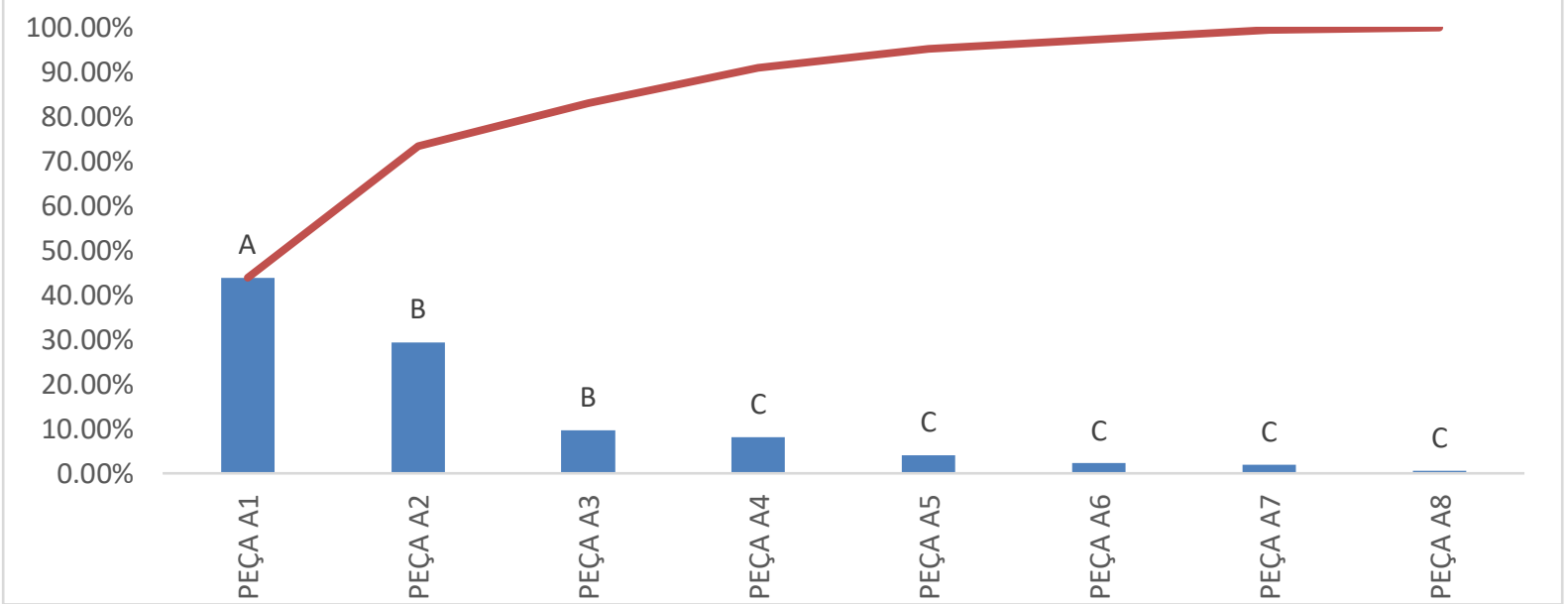

Fonte: Autores (2020)

Nota: $\%$ acumulado

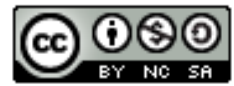


Nota-se que o item mais relevante é a peça A1, a qual representa $43,88 \%$ do valor total descartado. Logo em seguida vem a peça A2, com 29,43\% do valor total. Portanto os dois somam juntos quase $75 \%$ do valor total descartado $(\mathrm{R} \$ 1.072,76)$ em itens vencidos do Fornecedor X referente ao ano de 2018.

No caso do fornecedor Y, a peça B1 apresenta a maior porcentagem em relação ao valor total, representando $19,19 \%$ e a peça B2 com $14,45 \%$. Portanto juntas elas representam $33,64 \%$ do valor total descartado $(\mathrm{R} \$ 21.781,38)$ (Figura 3).

Figura 3. Curva $\mathrm{ABC}$ do fornecedor $\mathrm{Y}$.

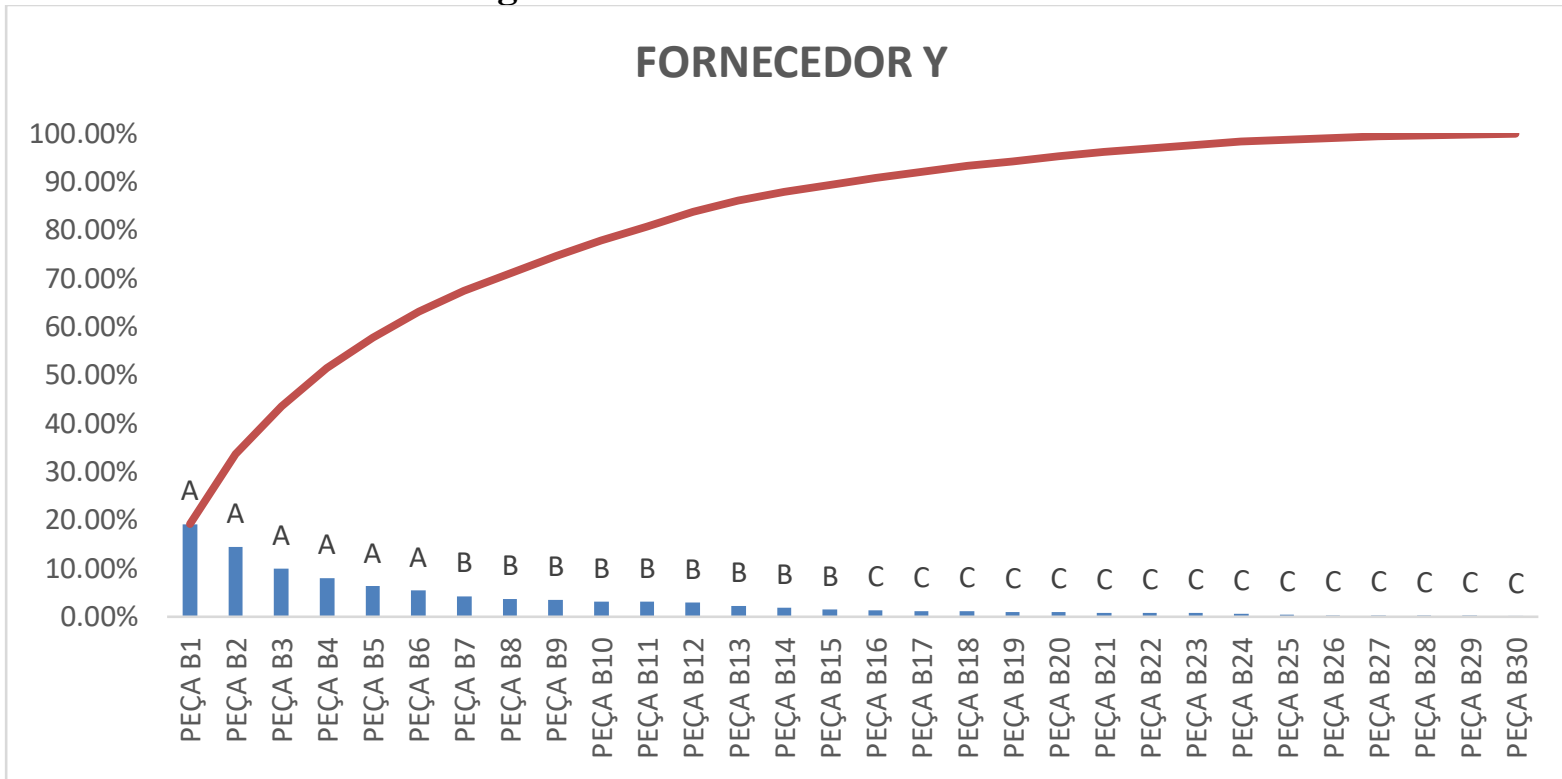

Fonte: Elaborado pelos autores (2020)

Nota: — \% acumulado

Após selecionar os quatro itens com maior relevância de descarte no ano de 2018, foram coletados dados importantes para comparação e justificativa dos vencimentos de cada item, como: lote econômico de compras, validade e demanda média anual (Tabela 1).

Tabela 1. Lote mínimo, validade e demanda das peças

\begin{tabular}{lcccc} 
& ITEM & $\begin{array}{c}\text { LOTE MÍNIMO } \\
\text { (peças) }\end{array}$ & $\begin{array}{c}\text { VALIDADE } \\
\text { (meses) }\end{array}$ & $\begin{array}{c}\text { DEMANDA MÉDIA ANUAL } \\
\text { (peças) }\end{array}$ \\
\hline \multirow{2}{*}{ FORNECEDOR X } & PEÇA A1 & 200 & 12 & 600 \\
& PEÇA A2 & 200 & 12 & 19.000 \\
\hline \multirow{2}{*}{ FORNECEDOR Y } & PEÇA B1 & 2.500 & 12 & 4.400 \\
& PEÇA B2 & 5.000 & 12 & 19.000 \\
\hline
\end{tabular}

Fonte: Autores (2020)

Nota-se que o lote mínimo de compras efetuadas pela empresa ao Fornecedor $\mathrm{X}$ é menor que o do Fornecedor Y, enquanto as demandas anuais de um item de cada um dos fornecedores se aproximam, possibilitando assim a comparação quanto a influência do tamanho da demanda em relação ao lote mínimo. Para isso foram levantados os seguintes dados dos itens, de acordo com a Tabela 2: quantidade comprada no ano de 2018, em unidade e valor monetário, e quantidade descartada, em unidade e valor monetário.

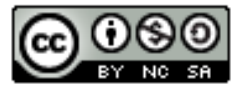


Citação (APA): Fenili, G. C., Araújo, F., de, Santos, A. G., dos, Calife, N. F. S., \& Rosa, V. A. de O. (2021). Análise da influência do lote mínimo de compras no controle de estoque de uma empresa automobilística. Brazilian Journal of Production Engineering, 7(5), $299-311$.

Tabela 2. Compras e descartes em unidade e valor

\begin{tabular}{lccccc} 
& ITEM & $\begin{array}{c}\text { COMPRA } \\
\text { (peças) }\end{array}$ & $\begin{array}{c}\text { COMPRA } \\
(\mathbf{R} \$)\end{array}$ & $\begin{array}{c}\text { DESCARTE } \\
\text { (peças) }\end{array}$ & $\begin{array}{c}\text { DESCARTE } \\
(\mathbf{R} \$)\end{array}$ \\
\hline \multirow{2}{*}{ FORNECEDOR X } & PEÇA A1 & 1.200 & $\mathrm{R} \$ 631,32$ & 600 & $\mathrm{R} \$ 315,66$ \\
& PEÇA A2 & 20.000 & $\mathrm{R} \$ 8.663,60$ & 239 & $\mathrm{R} \$ 103,53$ \\
\hline \multirow{2}{*}{ FORNECEDOR Y } & PEÇA B1 & 10.000 & $\mathrm{R} \$ 8.677,46$ & 4.818 & $\mathrm{R} \$ 4.180,80$ \\
& PEÇA B2 & 25.000 & $\mathrm{R} \$ 13.147,50$ & 5.985 & $\mathrm{R} \$ 3.147,51$ \\
\hline
\end{tabular}

Fonte: Autores (2020)

Após análise da Tabela 2, é possível notar que o índice de descarte da peça A1 é 50\%, visto que foram compradas 1.200 peças e descartadas 600 peças. Nesse caso, acredita-se que não houve influência do tamanho do lote mínimo de compras, já que o valor descartado corresponde a três vezes o lote mínimo da peça. Inúmeras causas podem ter causado esse descarte, como uma compra não assertiva, um cancelamento de produção do veículo que utilizava essa peça ou até um erro do fornecedor ao entregar as peças com validade menor que 12 meses.

Quanto a peça A2, nota-se que esta deteve uma alta demanda no ano de 2018 e baixo índice de descarte, visto que foram descartadas apenas $1,2 \%$ da quantidade total comprada. Diante disso, entende-se que o tamanho do lote mínimo negociado, 200 peças, foi eficiente para esse item. Portanto, conclui-se que para o Fornecedor X não é necessário a renegociação de tamanho de lote mínimo.

Em relação as peças do Fornecedor Y, para a peça B1, o índice de descarte foi de $48 \%$ das peças compradas. O lote mínimo desse item corresponde a 56\% da sua demanda média anual (4.400 peças), o que dificulta o processo de compra, visto que, com a atual situação o ideal seria terem sido feitas apenas duas compras desse item no ano todo. E dentro de uma empresa automobilística é normal que tenha mudanças na programação de produção durante o ano. Ressalta-se que mesmo que tivessem sido feitas apenas duas compras do item, ainda sim teria gerado descartes por vencimento.

A respeito da peça $\mathrm{B} 2$, esta possuiu uma demanda alta durante o ano, porém o seu lote mínimo também é alto, este corresponde a aproximadamente $25 \%$ da demanda média anual (19.000). Possuindo a mesma demanda, as peças A2 e B2 podem ser comparadas quanto à eficiência do tamanho do lote mínimo negociado. Enquanto o índice de descarte da peça A2 é 1,2\%, o da peça $\mathrm{B} 2$ foi de $23,9 \%$. O que nos contata que o tamanho do lote mínimo de compras influencia diretamente na gestão de compras de um item.

$\mathrm{LEC}=\sqrt{\frac{(2 * \mathrm{CP}) * \mathrm{D}}{\mathrm{CA}}}$

$\operatorname{LEC}($ peça B1 $)=\sqrt{\frac{(2 * 8678) * 4400}{300}}=504$ peças.

LEC (peça B2) $=\sqrt{\frac{(2 * 13147) * 19000}{300}}=1.290,5$ peças.

Na Tabela 3, segue sugestão de lote mínimo de compras para o Fornecedor Y, calculado pela equação 1 . 
Tabela 3. Sugestão de lote mínimo de compras

\begin{tabular}{lcc} 
& ITEM & SUGESTÃO DE LOTE MÍNIMO (peças) \\
\hline \multirow{2}{*}{ FORNECEDOR Y } & PEÇA B1 & 500 \\
& PEÇA B2 & 1.200 \\
\hline
\end{tabular}

Fonte: Autores (2020)

Foram feitas as razões entre as quantidades descartadas de cada fornecedor sobre a quantidade comprada do mesmo. Para o Fornecedor X, a quantidade descartada das peças A1 e A2 corresponde a 4,51\%, ao passo que o Fornecedor Y tem 33,5\% das peças B1 e B2 descartadas. Portanto, é necessário que seja renegociado os lotes mínimos de compras do Fornecedor Y (peças B1 e B2), a fim de minimizar os mesmos, possibilitando então que o comprador da peça tenha mais maleabilidade do processo de compra em resposta as mudanças e dificuldades do dia a dia. Para isso, com auxílio da Eq. (1), foi calculado o lote mínimo ideal para as duas peças do Fornecedor Y, peça B1 e peça B2, utilizando os dados (CP e CA) fornecidos pela empresa estudada.

\section{ConcluSÃo}

Este estudo buscou com objetivo apresentar uma proposta de melhoria para analisar a influência da negociação de lote mínimo de itens perecíveis em uma indústria automobilística, com o intuito de findar o problema de descarte de itens vencidos. A pesquisa foi realizada para expor a ineficiência dos itens que possuíam lote mínimo de compras alto, enquanto comparados com seu o índice de descarte. Após análise dos dados, ficou claro que o objetivo da pesquisa foi alcançado, uma vez que os resultados encontrados apontaram que os itens do Fornecedor X, apresentaram lote mínimo de compras menor com índice de descarte mais baixo $(4,51 \%)$, enquanto os itens do Fornecedor Y, que eram comprados por meio de lote mínimos elevados, indicaram um índice de descarte maior $(33,5 \%)$, necessitando de uma renegociação com o fornecedor.

Os fornecedores ( $\mathrm{X} \mathrm{e} \mathrm{Y}$ ) possuem a mesma demanda, as peças A2 e B2, porém apresentam lote mínimo diferenciados. Destaca-se que o índice de descarte da peça A2 é 1,2\%, o da peça B2 foi de $23,9 \%$. Contata-se que o tamanho do lote mínimo de compras influencia diretamente na gestão de compras de um item.

Para responder à pergunta de pesquisa sobre qual o método mais adequado para a gestão de produtos perecíveis de modo a minimizar perdas por vencimento da data de validade? Destacase que a curva $A B C$ indicou os itens de maior descarte e em seguida foram verificados os índices para análise do lote mínimo para renegociação com os fornecedores.

Portanto, com tantas barreiras que influenciam o processo de gestão de compras de itens perecíveis, a alteração do lote mínimo para o menor valor negociável possível, representa um ganho para a empresa, pois possibilita ao comprador da peça lidar com as mudanças e restrições da rotina empresarial com maior maleabilidade.

Além da proposta de renegociação acredita-se que a implementação do JIT pode apresentar fortes possibilidades de reduzir os custos de perecibilidade dos produtos e minimizar os custos, uma vez que o JIT engloba conceitos de qualidade, entregas em intervalos de tempo curto, que permite ter estoques reduzidos evitando assim obsolescência, deterioração dos materiais e menores imobilizações de capital investido em materiais em estoque.

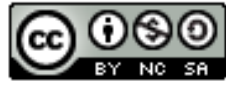


Citação (APA): Fenili, G. C., Araújo, F., de, Santos, A. G., dos, Calife, N. F. S., \& Rosa, V. A. de O. (2021). Análise da influência do lote mínimo de compras no controle de estoque de uma empresa automobilística. Brazilian Journal of Production Engineering, 7(5), $299-311$.

\section{REFERÊNCIAS}

Aaker, D. A., Kumar, V., \& Day, G. S. (2004). Pesquisa de marketing. tradutor: Reynaldo Cavalheiro Marcondes.

Accioly, F., Ayres, A. De Pádua S., Sucupira, C. (2012) Gestão de estoques. 1 ed. $3^{\text {a }}$ reimpressão. Rio de Janeiro, RJ: FGV.

de Araújo, S. A., Librantz, A. F. H., \& Alves, W. A. L. (2009). Algoritmos genéticos na estimação de parâmetros em gestão de estoque. Exacta, 7(1), 2130. https://doi.org/10.5585/exacta.v7i1.1207

Baily, P. et al., (2000). Compras: Princípios e Administração. São Paulo: Atlas.

Ballou, R. H. (2001). Logística Empresarial: Transportes, Administração de Materiais e Distribuição Física. São Paulo: Atlas, 1993; Ballou, Ronald H. Gerenciamento da Cadeia de Suprimentos: Planejamento, organização e logística empresarial. $4^{\mathrm{a}}$ Edição. Porto Alegre: Bookman.

Ballou, R. H. (2011). Logística Empresarial: Transportes, Administração de materiais e Distribuição Física; São Paulo, Editora Atlas.

Bányai, T., \& Bányai, Á. (2017). Modelling of just-in-sequence supply of manufacturing processes. In MATEC Web of Conferences, 112, p. 06025). EDP Sciences.

Bornia, A. C. (1995). A utilização do método da unidade de esforço de produção na quantificação das perdas internas da empresa. In Anais do Congresso Brasileiro de Custos$A B C$.

Braga, M. (1996). In Gestão do Aprovisionamento, gestão de compras, stocks e armazéns. Lisboa: Editorial Presença.

Braga, A. (2006). Evolução estratégica do processo de compras ou suprimentos de bens e serviços nas empresas. Instituto Coppead, Universidade Federal do Rio de janeiro, Rio de Janeiro.

Carvalho, J. M. C. (2002). Logística. 3.ed. Lisboa: Edições Silabo.

Carvalho, C. (2010). In Logística e Gestão da Cadeia de Abastecimento (2 ${ }^{\mathrm{a}}$ ed.). Lisboa: Edições Sílabo.

Maia, J. L. \& Cerra, A. L. (2006). Gestão da cadeia de suprimentos e estratégia logística: casos em fornecedores automotivos. Sistemas \& Gestão, 1(3), 174-194.

Cerra, A. L. \& Maia, J. L. (2008). Desenvolvimento de produtos no contexto das cadeias de suprimentos do setor automobilístico. Revista de Administração Contemporânea, 12(1), 155176.

Ching, H. Y. (2001.) Gestão de estoques na cadeia de logística integrada. São Paulo: Editora Atlas SA.

Corrêa, H. L., Gianesi, I. G., \& Caon, M. (2001). Planejamento, programação e controle da produção. São Paulo: Atlas, 1.

Dias, M. A. P. (2010). Administração de Materiais: Princípios, Conceitos e Gestão. 6. ed. São Paulo: Editora Atlas SA.

Dicken, P. (2010) Mudança global: mapeando as novas fronteiras da economia global. Porto Alegre: Bookman

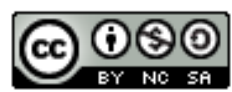


Citação (APA): Fenili, G. C., Araújo, F., de, Santos, A. G., dos, Calife, N. F. S., \& Rosa, V. A. de O. (2021). Análise da influência do lote mínimo de compras no controle de estoque de uma empresa automobilística. Brazilian Journal of Production Engineering, 7(5), $299-311$.

Gaither, N. \& Frazier, G. (2001). Administração da Produção e Operações, 8 ed. São Paulo: Editora Pioneira.

Gerhardt, T. E. \& Silveira, D. T. (2009). Métodos de Pesquisa. $1^{\text {a }}$ Ed. Porto Alegre. Plageder

Godinho Filho, M., Hayashi, A. P., \& Rufo, C. R. (2013). Uso da abordagem Quick Response Manufacturing para a redução do lead time em uma empresa do setor calçadista. Anais do XXXIII enegep - Encontro Nacional de Engenharia de Produção.

Gonçalves, P. S. (2013). Administração de Materiais. 4. ed. Rio de Janeiro: Elsevier.

Ghinato, P. (2000). Produção \& Competitividade: Aplicações e Inovações, Ed.: Adiel T. de Almeida \& Fernando M. C. Souza, Edit. da UFPE, Recife, Publicado como $2^{\circ}$ cap. do Livro.

Iman. (2015). Estratégia para Acurácia. Revista Logística e Supply Chain. Recuperado de https://www.imam.com.br/logistica/artigos/serie-gestao-de-estoques/2288-estrategias-paraacuracia

Junior, F. R. L. \& Carpinetti, L. C. R. (2019). Análise das práticas de gestão de cadeias de suprimento de uma empresa do setor automobilístico. Brazilian Journal of Development, 5(7), 10319-10332.

Kawase, F. S. \& De Paula, L. L. (2012). A importância do gerenciamento do estoque no setor Supermercadista de pequeno porte na cidade de Lins-SP. Trabalho de Conclusão de Curso apresentado a Faculdade de Tecnologia de Lins Prof. Antônio Seabra, Lins, São Paulo.

Kischner, P. \& Viegas, T. D. O. C. (2018). Política industrial para o setor automobilístico entre 2000 e 2015. Economia e Desenvolvimento, 30, 5.

Kogik, A. V., Da Silva, A. M., Belusso, M., \& Werlang, R. (2018). A Importância Do Gerenciamento Estratégico Do Estoque No Setor Supermecadista. Anais Da Engenharia De Produção/Issn 2594-4657, 2(1), 1-20.

Letti, G. C. \& Gomes, L. C. (2014). Curva ABC: melhorando o gerenciamento de estoques de produtos acabados para pequenas empresas distribuidoras de alimentos. Update-Revista de Gestão de Negócios, 1(2), 66-86.

Manuel, E. M. H. D. A. (2013). Planeamento e Gestão de materiais O paradigma Just in time versus constituição de stocks Gestão técnica de materiais perecíveis na ótica de abastecimento (Doctoral dissertation).

Martins, P. G. \& Alt, P. R. C. (2006). Administração de materiais e recursos patrimoniais. São Paulo: Saraiva.

Medina, H. V. D. \& Gomes, D. E. B. (2003). Reciclagem de automóveis: estratégias, práticas e perspectivas. CETEM.

Moreira, D. A. (2009). Administração da produção e operações. 2a edição. CLS - Cengage Learning, São Paulo.

Paoleschi, B. (2014). Estoques e Armazenagem. $1^{\text {a }}$ edição. São Paulo Érica.

Pereira, D. M. \& Leite, J. P. (2016). Implantação de layout celular na montagem de cadernos. Veredas Favip-Revista Eletrônica de Ciências, 9(1), 58-74.

Polit, D. F., Becker, C. T., \& Hungler, B. P. (2004). Fundamentos de pesquisa em enfermagem: métodos, avaliação e utilização. Trad. de Ana Thorell. 5. ed. Porto Alegre: Artmed. 
Pozo, H. (2000). Administração de recursos materiais e patrimoniais: uma abordagem logística. Editora Atlas SA.

Reis, L. D. \& Paulino, A. (1994). Gestão dos stocks e compras. Editora Internacional, Lisboa.

Santana, M. L. \& Piper, H. Proposta de melhoria de layout e a curva ABC no setor de estoque: um estudo de caso. Revista Ciência (In) Cena, v. 1, n. 5, p. 30-50, jul./dez. 2017. Recuperado de http://periodicos.estacio.br/index.php/cienciaincenabahia/article/viewFile/3241/pdf3241

Santos, R. S. D., Schmidt, R., Adami, V. S., \& Schmidt, F. C. (2021). Análise dos efeitos do Novo Regime Automotivo (1996-1999) e o Inovar-Auto (2012-2017). Brazilian Journal of Political Economy, 41, 137-154.

Sheldon, D. H. (2004). Achieving Inventory Accuracy: A Guide to Sustainable Class A Excellence in 120 Days. J. Ross Publishing.

Shingo, S. (1996). O sistema Toyota de produção. Bookman Editora.

Silva, M. V. \& da Silva Martins, M. K. (2015). Just In Time E As Relações De Trabalho Na Montadora Mitsubishi Motors Do Brasil Sa.

Slack, N., Chambers, S., \& Johnston, R. (2009). Administração da produção. $3^{\text {a }}$. Edição São Paulo Editora Atlas.

Wanke, P. (2000). Gestão de estoques. In: Fleury, P.F.; Figueiredo, K.; Wanke, P. (Org.). Logística empresarial. São Paulo: Atlas, 2000. p. 177-208. Coleção COPPEAD de Administração.

Wanke, P. (2012). Quadro conceitual para gestão de estoques: enfoque nos itens. Gestão \& Produção, 19(4), 677-687.

Wood, S. (1991). O modelo japonês em debate: pós-fordismo ou japonização do fordismo. Revista Brasileira de ciências sociais, 17(6), 28-42.

Wood Jr., T. (1992). Fordismo, toyotismo e volvismo: os caminhos da indústria em busca do tempo perdido. Revista de administração de Empresas, 32(4), 6-18.

Yin, R. K. (2001). Estudo de caso: planejamento e métodos. 2.ed. Porto Alegre: Bookman. 